\title{
La idea imperial en Virgilio
}

\author{
The imperial idea in Vergil \\ RuBÉN OLMO LÓPEZ* \\ Universidad Complutense de Madrid
}

\begin{abstract}
RESUMEN
ABSTRACT

La Eneida de Virgilio es la gran epopeya del pueblo romano no sólo por evocar sus orígenes, sino por revelar las características de la idea imperial romana. Ésta está basada en los valores romanos que fueron destacados en el principado augusteo y en el modelo romano de sociedad, cuya esencia descansaba en los principios constituyentes de su ciudadanía.

\section{PALABRAS CLAVE}

Vergil's Aeneid is the great epic poem of roman people not only for evocating their origins, but for turning out the characteristics of roman imperial idea. It's based on the roman values that were stood out in the augustan principate and on the roman model of society, whose essence laid on the constituent principles of its citizenship.

\section{KEYWORDS}

Eneida, Augusto, idea imperial, pietas, valores romanos, sociedad civil.

Aeneid, Augustus, imperial idea, pietas, augustan values, civil society.

\section{INTRODUCCIÓN ${ }^{1}$}

Augusto, una vez asentado en el poder, se propuso regenerar el proyecto imperial romano y recuperar la fe de la población en él, asegurándole una nueva era de paz y prosperidad². Para llevar adelante este propósito era consciente de que

* Dirección postal: Calle Madanela 5, 4. ${ }^{\circ}$ A, 27002, Lugo. Correo electrónico: castirubolmo $@$ hotmail.com

1 Quiero expresar mi agradecimiento hacia las personas que leyeron este artículo antes de su publicación: mi maestro, Pedro López Barja, quien me dio la idea del mismo y me aconsejó con su cercanía y agudeza habituales, Estela García Fernández y Javier Andreu Pintado, quien amablemente me invitó a publicarlo. Cualquier error contenido en estas páginas es exclusivamente responsabilidad mía.

${ }^{2}$ Lo expresó con gran acierto P. Grimal al decir que «Augusto supo proponer, a ese mundo a la deriva, no tanto un nuevo sistema como una nueva justificación de cuanto en el antiguo sistema seguía siendo viable», concluyendo que «el Siglo de Augusto quedó inaugurado justo cuando el olvido comenzó a caer sobre los episodios sangrientos, el día en que el pensamiento romano volvió a encontrar, gra- 
no bastaba con un gobierno acertado y una renovación de las élites y del entramado administrativo romano, por mucho que así se atendiesen mejor las necesidades materiales del Imperio. Augusto necesitaba un respaldo ideológico, que basó en sus propias convicciones (teniendo como referencia los mores maiorum, algo muy propio en un aristócrata romano) y que canalizó a través de la obra de los poetas del círculo de Mecenas. Entre ellos sobresalió Virgilio, el más político en sus registros, quien probablemente fue el que compartió en mayor medida con el princeps la idea que éste tenía de Roma. Ésta quedó plasmada en su obra capital, la Eneida, la cual, además de convertirse en la gran epopeya del pueblo romano, fue todo un canto justificador de la idoneidad de su idea imperial y la legitimidad de la misma. A partir de ella expondremos en qué conceptos y realidades se cimentó tal idea imperial, marcada desde Virgilio, como observaremos, por el mundo de las imágenes del principado augusteo.

\section{UN IMPERIO, UNA LEGITIMIDAD}

Las élites que todo imperio tiene tras de sí sienten siempre la necesidad de elaborar un discurso legitimador del orden mundial que representan. Su vocación universal como imperio - a diferencia de un mero estado hegemónico- les obliga a ello. El proyecto imperial ha de tener un respaldo ideológico fuerte, que cale en la población que queda asumida dentro de él e implique a sus clases altas, garantizando que sus intereses no corran peligro alguno.

Todos los imperios encuentran en la aspiración a la paz - una paz perdurable- una justificación muy socorrida. Se acogen a la idea de que sólo una estructura política a gran escala puede mantener un estado de paz estable a largo plazo, dada su capacidad de acción (que ofrecía mayor seguridad frente a las amenazas externas, aniquilándolas o integrándolas tras un proceso de civilización), sus recursos y su naturaleza universal, ajena a las fronteras de un simple estado. A esa paz iría unida una prosperidad que se beneficiaría del orden imperial protector.

Esa garantía de paz, sin embargo, es sólo una pieza dentro del programa ideológico de los imperios. Estos siempre presentan, además de su capacidad de acción, una misión que otorga a su orden y actuación un carácter sagrado. En los siglos XV, XVI y XVII, el Imperio Hispánico se proclamaba verdadero defensor de la catolicidad frente a turcos y protestantes, y evangelizador de los pueblos del Nuevo Mundo. En el XIX, el Imperio Británico se decía civilizador de los pueblos colonizados y garantizador del buen discurrir del mercado mundial para los intereses de su burguesía. Actualmente, EEUU se presenta como exportador de la democracia y de un neoliberalismo supuestamente necesario. Todos, en fin, tienen una misión que justifica su existencia. También Roma la tuvo en su momento ${ }^{3}$.

cias a la obra naciente, su fe en sí mismo después de la prolongada desesperación de las guerras civiles». GRIMAL, P. El siglo de Augusto, Madrid, FCE, 1996, p. 15.

3 Para todo lo antedicho ver MÜNCKLER H. Empires: The Logic of World Domination from Ancient Rome to the United States, Cambridge Polity Press, 2007, pp. 81-107. 
En la Eneida, Virgilio plasmó la misión de Roma, vaticinada por los dioses y refrendada por su historia:
«Excudent alii spirantia mollius aera,
credo equidem, uiuos ducent de marmore uultus, orabunt causas melius, caelique meatus
describent radio et surgentia sidera dicent:
tu regere imperio populos, Romane, memento
hae tibi erunt artes: pacisque imponere morem,
parcere subiectis et debellare superbos ${ }^{4}$.

El poeta no puede ser más explícito. Anquises transmite a Eneas los tres puntos fundamentales de la misión sagrada que Roma, como imperio que es (o que será, si atendemos al tiempo interno de la obra), tiene: asegurar la paz a través de la ley y de los pactos, ser justo y clemente con los vencidos y castigar a aquellos que amenacen el cumplimiento de este destino, poniendo en peligro la paz y la prosperidad que a él van unidas. Esos vencidos y esos soberbios son los pueblos bárbaros, los cuales serían perdonados y, con el tiempo, integrados en las dinámicas generales del imperio si se avenían a colaborar con sus dominadores haciéndose acreedores de ese honor, o bien castigados si traicionaban los sagrados pactos establecidos con Roma. Pero más allá de evocar las antedichas realidades, estos versos nos interesan al presentar, condensados, los elementos típicamente justificadores de un imperio y que recorren repetitivamente todo el poema virgiliano: paz, seguridad, orden y prosperidad perdurables.

Augusto, tras su victoria en Actium, se presentaba como el salvador de Italia y del imperio: había instaurado un orden universal perdurable, un kosmos, superando el chaos del último siglo. En esa batalla, como muestra el escudo que Vulcano le fabrica a Eneas en el libro VIII, los dioses están de su parte; pero de ellos hablaremos más adelante. Ahora nos interesa la idea de un orden universal que se alcanza gracias al princeps y que da nueva vida y justifica el imperio de los romanos. En ese sentido, la guerra culminada en Actium había sido una guerra justa, ya que con ella se había buscado establecer el orden y la paz. El concepto de bellum pium et iustum, tan importante dentro del pensamiento romano, determina su conducta imperialista ${ }^{5}$. Si nos remitimos a Cicerón —quien reflexionó acerca de este concepto- la guerra justa sería aquella que se emprende con el fin de vivir en paz sin sufrir injusticia. Esa paz, además, venía asegurada por los pactos, que el romano consideraba sagrados ${ }^{6}$. En Italia, Eneas lucha por la paz y, además, contra un enemigo, Turno, que no ha respetado los pactos acordados ${ }^{7}$. Por su parte, también Au-

4 VIRGILIO. Aeneis. VI, 847-853.

5 BRUNT, P. A. «Laus Imperii», en en GARNSEY, P. D. A; WHITTAKER, C. R. (eds.) Imperialism in the Ancient World. Cambridge University Press, 1978 (pp. 159-191), pp. 175-178.

${ }^{6}$ LÓPEZ BARJA DE QUIROGA, P. Imperio legítimo: El pensamiento político romano en tiempos de Cicerón. Madrid, Antonio Machado Libros, 2006, pp. 275-290.

7 En el Libro VII, Turno no acepta el pacto establecido entre el rey Latino y Eneas - por el que su pueblo y el troyano se unían y Eneas recibía en matrimonio a la hija de Latino, Lavinia- y se levanta en armas contra los troyanos. Galinsky ha resaltado que incluso esa guerra fue pía y justa, a pesar de la brutalidad que Eneas demuestra con su enemigo. GALINSKY, K. Augustan culture: An interpretative introduction. Pinceton University Press, 1998, p. 249. 
gusto se había valido de una guerra para instaurar la paz; éste, como Eneas, un joven héroe escogido por los dioses para liderar un pueblo en ruinas. Las concomitancias entre ambos personajes son notables ${ }^{8}$.

El poeta - como el propio Augusto - reconoce la importancia que la guerra ha tenido en la historia del pueblo romano, una de cuyas virtudes más destacadas es su uirtus ${ }^{9}$. Esa valía en el ámbito de la guerra le había proporcionado la superioridad necesaria para abatir a sus enemigos y forjar su dominación sobre el mundo conocido. Pero una vez logrado el imperio, quedaba el reto de conservarlo. En la Eneida se señala que el princeps opta por la paz como nuevo vehículo que asegure la prosperidad, la seguridad y la perdurabilidad del Imperio. Una prosperidad que no es sólo romana, sino universal. El Imperio Romano trasciende los límites de la Urbs, que pasa a confundirse con el Orbs ${ }^{10}$ : Roma deja de ser una ciudad dominante y se convierte así en una idea universal. El orden romano es el orden del universo.

Ese orden universal es el garante de la sagrada paz. Al igual que las ideas que funcionan como fundamento de la cohesión social, la Concordia y la Fides, la Pax recibe culto en Roma. El Ara Pacis Augustae es un monumento que exalta los beneficios derivados de la paz conseguida por el esfuerzo del princeps, digno sucesor de los míticos fundadores de Roma, Eneas y Rómulo, bajo el amparo de los dioses. La prosperidad propia de los reinos de Saturno está plasmada en los relieves del Altar, tanto en la alegoría de Tellus como en los motivos florales que recorren la mitad inferior de sus paramentos externos ${ }^{11}$. Una paz profetizada por Júpiter al comienzo de la Eneida:

«Nascetur pulchra Troianus origine Caesar, imperium oceano, famam qui terminet astros, lulius, a magno demissum nomen lulo.

Hunc tu olim caelo, spoliis Orientis onustum, accipies secura; uocabitur hic quoque uotis. Aspera tum positis mitescent saecula bellis; cana Fides et Vesta, Remo cum fratre Quirinus, iura dabunt; dirae ferro et compagibus artis claudentur belli portae... ${ }^{12}$

8 Virgilio, al igual que Augusto, supo aprovechar las ventajas que le ofrecía la figura de Eneas, frente a un Rómulo que, además, de recordar a la monarquía, había cometido un fratricidio, traicionado un pacto (con los Sabinos), y había sido asesinado por una conjuración de senadores, según una versión de la leyenda. Vid. MAS, S. Pensamiento romano: Una historia de la filosofía en Roma, Valencia, Tirant lo Blanch, 2006, pp. 243-244. A. Rdguez. Mayorgas ha demostrado cómo la figura de Eneas no formaba parte de la memoria cultural del pueblo romano. RODRíGUEZ MAYORGAS, A. La memoria de Roma: oralidad, escritura e historia en la República romana. Oxford, BAR International Series 1641, 2007.

9 «Proximum a dis immortalibus honorem memoriae ducum praestitit, qui imperium p. R. ex minimo maximum reddidissent». SUETONIO. Diuus Augustus, 31. Véase la galería de Summi Viri que mandó construir en su Foro.

10 Famoso símil ovidiano (OVID. Fasti 2, 688-689).

11 ZANKER, P. Augusto y el poder de las imágenes. Madrid, Alianza Editorial, 2005, pp. 208-220.

12 Aen. I, 286-294. Así consuela Júpiter a Venus ante la visión de los padecimientos que sufría Eneas durante su viaje. Las puertas de la guerra a las que se hace referencia son, evidentemente, las del templo de Jano en Roma que Augusto se vanagloriaba de haber cerrado en tres ocasiones (Res Gestae 13). 
La loa a la Pax Augusta es evidente. Una paz que se consiguió tras una dura guerra y muchos padecimientos (como los de Eneas) y que dio comienzo, tras la significativa victoria en Actium, al cumplimiento definitivo del destino imperial romano. Augusto y su principado son la culminación de la historia de Roma, y de él dice el poeta por boca de Anquises:

«Hic uir, hic est, tibi quem promitti saepius audis, Augustus Caesar, diui genus, aurea condet saecula qui rursus Latio regnata per arua Saturno quondam, super et Garamantas et Indos proferet imperium: iacet extra sidera tellus, extra anni solisque uias... ${ }^{13}$

Ahí está: la nueva Edad de Oro ha llegado, y con ella la felicitas derivada de la prosperidad y la abundancia. Con Augusto se renueva el pacto entre los romanos y sus dioses y Roma vuelve a confiar en su futuro, resurgida de su ruina y extendido su dominio a los confines del mundo conocido (de ahí la cita de garamantes e indios) ${ }^{14}$. Leído el último verso («extra anni solisque uias...») es inevitable acordarse de la coraza de la estatua de Prima Porta, en la que se representa, en su pectoral, al Sol en su carro recorriendo el cielo, en una alegoría de la aeternitas del Imperio ${ }^{15}$ y del dominio de Roma, encabezada por su princeps, sobre el orbe. Tal universalidad de Roma queda confirmada ya en el primer libro, también dentro de la profecía de Júpiter, en los famosos versos que dicen: «His ego nec metas rerum nec tempora pono: imperium sine fine dedi» $\$$.

He aquí una de las sentencias más precisas e impactantes que realiza Virgilio en su obra acerca de la naturaleza del Imperio. Un imperio sin fronteras de ningún tipo es un imperio universal y eterno, es decir, un imperio legítimo como ningún otro conocido, ya que, por deseo divino, puede proporcionar la antedicha paz duradera, que además se basa en el poder de la ley, en la justicia. Roma no es una vil dominadora del mundo, ni una potencia hegemónica que acabará decayendo; no, Roma se identifica aquí con el propio orbe, y su orden es el del universo. Este planteamiento conoce su plasmación real gracias al modelo de sociedad en el que el imperio se fundamenta.

13 Aen. VI, 791-796.

14 Virgilio retoma aquí el vaticinio que precipitadamente había hecho en su Cuarta Égloga en el 40 a.C: «Ultima Cumaei uenit iam carminis aetas;/ magnus ab integro saeclorum nascitur ordo/ lam redit et Virgo, redeunt Saturnia regna,/ iam noua progenies caelo demittitur alto./ Tu modo nascent puero, quo ferrea primum / desinet ac toto surget gens aurea mundo,/casta faue Lucina; tuus iam regnat Apollo». Eglogae. IV 4-10.

${ }_{15}$ Paul Zanker ha interpretado de forma excelente el contenido iconológico de la coraza. ZANKER, P., op. cit. pp. 228-229.

Otros versos que transmiten la misma idea plasmada en la coraza: «ne pete conubiis natam sociare Latinis, / o mea progenies, thalamis neu crede paratis; / externi uenient generi, qui sanguine nostrum / nomen in astra ferant, quorumque a stirpe nepotes / omnia sub pedibus, qua sol utrumque recurrens / aspicit Oceanum, uertique regique uidebunt", le dice Fauno a su hijo Latino, para persuadirlo de que se una a los troyanos. Aen. VII, 96-101.

16 Aen. I, 278-279. 
La idea imperial romana se afirmó gracias a que estaba sustentada, en la realidad cotiadiana, en dos fuertes pilares: el sistema municipal y la ciudadanía. Esta última fue la pieza clave de lo que se puede denominar como modelo romano de sociedad. Roma - a partir de la Guerra de los Aliados, tras la que el ser romano adquiere una nueva dimensión ${ }^{17}$ — presenta un modelo de sociedad abierto, integrador, al tener por fundamento el ius. Los elementos étnicos carecían de relevancia en la caracterización del romano, que era ante todo un ciudadano. Cierto es que se dio gran diversidad entre provincias, y que la romanización discurrió en cada caso por distintos cauces, pero hay un modelo social siempre presente y un único referente que da carta de naturaleza a la persona, la ley. Cicerón fue quien teorizó lo que entrañaba este modelo de sociedad cívica. Recuérdese el famoso pasaje del De Re Publica en el que dice: «... res publica res populi, populus autem non omnis hominum coetus quoquo modo congregatus, sed coetus multitudinis iuris consensu et utilitatis communione sociatus ${ }^{18}$. Virgilio, por su parte, también insiste en el valor de la justicia como pilar de la sociedad y del orden ${ }^{19}$.

«En Roma», dice Syme, «la disminución de la cepa indígena estaba paliada y compensada por una virtud singularmente escasa en las ciudades-estados de Grecia, pero inculcada a Roma desde sus primeros tiempos por las necesidades militares de la República, a saber: la disposición a acoger a nuevos miembros en el cuerpo cívico»20. He ahí la sociedad civil a la que aludimos, en la cual «la ley es el vínculo (...), y el derecho es la igualdad de la ley»21. En tiempos de Augusto, la constitución mixta había fracasado y, en su lugar, se instauró una nueva monarquía, que es un tipo puro de república para Cicerón. Por tanto, el modelo social seguía siendo el mismo, aunque la gestión de los asuntos que atañían al pueblo se llevase de una manera diferente a la del período anterior.

Lo que ahora nos interesa es que la innovadora sociedad que expande por el mundo el Imperio Romano es integradora, ya que no tiene en cuenta el lugar de procedencia de la persona, sino su status jurídico. La identidad personal en el Imperio depende del status jurídico del que se goce. La ciudadanía romana estaba al alcance de todos aquellos que se integrasen en el orden romano, aunque esto no

17 Véase SYME, R. La revolución romana, Madrid, Taurus, 1989, p. 568, donde habla del triunfo de los itálicos sobre Roma, con la su plena integración en el marco político, ciudadano, romano.

${ }_{18}$ CICERÓN. De re publica I, 39. Véase la importancia de la idea de una comunidad que se organiza en base a la armonía del derecho (iuris consensus). Vid. LÓPEZ BARJA DE QUIROGA, P., op. cit. pp. 201-206.

19 Le dice Júpiter a Venus acerca de Eneas que éste «bellum ingens geret Italia, populosque feroces / contundet, moresque viris et moenia ponet». Aen. I, 263-264.

llioneo, refiriéndose a Dido, dice: «O Regina, novam cui condere luppiter urbem / iustitiaque dedit gentis frenare superbas». Aen. I, 521-522). Aunque habla de Dido, Virgilio plasma aquí su visión de lo que debe conducir a la civilización: la justicia, que para Cicerón era el elemento sobre el que tenía que estar basada una república para ser considerada como tal. Vid. LÓPEZ BARJA DE QUIROGA, P., op. cit. pp. 219-221. En otro pasaje, cuando Eneas funda una ciudad en Sicilia con integrantes de su expedición al lado de lugar donde había erigido el túmulo de su padre, se narran los pasos generales seguidos en toda creación de una ciudad: trazado de sus límites, asignación de sus tierras, emplazamiento del foro, constitución de un senado y elaboración de sus leyes. Véase Aen. V, 755-760.

20 SYME, R., op. cit. p. 560.

21 CIC. De re pub. I, 49. 
quiere decir que fuese fácil conseguirla: era un bien precioso que no se podía conceder a la ligera para que no se degradase su valor, tal y como pensaba Augusto según Suetonio ${ }^{22}$. C. Moatti ha expresado con gran acierto la esencia de este modelo social: «lo romano no es algo predeterminado, sino precisamente aquello que el vínculo jurídico y cívico construye» ${ }^{23}$. Ahí reside el universalismo del imperio romano y la oportunidad de consumar su aeternitas ${ }^{24}$.

Eneas es el paradigma de romano dentro de un Imperio tan diverso. Es un bárbaro que llega a ser romano tras sufrir una paulatina transformación, palpable en su cambio de conciencia acerca de su identidad, acaecido en el libro $\mathrm{VI}$, que por ello se revela crucial en el esquema general de la obra ${ }^{25}$. De hecho, el pueblo romano nace de la fructífera unión de latinos y troyanos. Tiempo después - tal y como el relato tradicional de los orígenes de Roma cuenta-Rómulo acogerá en su recién fundada ciudad a todo aquel que quisiera asentarse allí.

No obstante, sí hay que señalar que ese proceso de integración, de consecución de la ciudadanía romana por parte de provinciales, no era posible sin que antes el territorio asumido por Roma no sufriese una fase de aculturación, es decir, de romanización. Un pueblo romanizado es un pueblo comprometido con la idea imperial romana, ya que ha asumido los valores de éste. Ha de ser matizado, sin embargo, que la romanización no fue un proceso de civilización, sino de implicación de las élites indígenas en la colaboración con el imperio romano en tareas de control del territorio y de la población. Es más, se pretendía que los vástagos de esas élites indígenas recibiesen una formación que los capacitaría como futuros administradores del imperio desde su provincia26. Esa educación estaría basada en el principio de la humanitas, que no ha de ser entendida como la monolítica civilización romana que se impone a la indígena, sino como un conjunto de valores y conductas aristocráticos (con los que las élites romanas se diferenciaban tanto del bárbaro como de la plebe) que podían ser asumidos a través de una esmerada educación y que daban una especial cualificación para el mando. En Virgilio, la humanitas es, además, una extensión de la pietas y, por tanto, otra cualidad de su Eneas, ya que no duda en unirse a los aborígenes del Lacio en una actitud de igual a igual. Dice Eneas:

«si nostrum adnuerit nobis uictoria Martem

ut potius reor et potius di numine firment,

22 SUETONIO, Diuus Augustus, 40.

23 MOATTI, C. La razón de Roma: El surgimiento del espíritu crítico a fines de la República. Madrid: Antonio Machado Libros, p. 446.

${ }^{24}$ El desempeño de magistraturas en un municipio de derecho latino daba acceso, como premio, a la ciudadanía romana. Por otra parte, incluso un esclavo podía aspirar a que su descendencia acabase formando parte de la comunidad como miembro de pleno derecho, ya que un hijo de liberto es un hombre nacido libre. El propio Quinto Horacio Flaco era hijo de un liberto. . Si bien es cierto que para ser eques equo publico se requería que el padre y el abuelo fuesen ingenui.

25 MAS, S., op. cit. p. 245.

${ }_{26}$ Véanse los esfuerzos de Agrícola en este sentido mientras fue gobernador de Britania durante el reinado de Domiciano (Tácito. Agricola 21). Marrou ya señaló en su momento la importancia que tuvo en el Imperio la extensión de la escuela romana y de su educación (MARROU, H.-I. Historia de la educación en la Antigüedad. Madrid, Akal, 2004, pp. 376-378). 
non ego nec Teucris Italos parere iubebo nec mihi regna peto: paribus se legibus ambae inuictae gentes aeterna in foedera mittant. Sacra deosque dabo... ${ }^{27}$.

Como es sabido, los romanos siempre adoptaron en los pactos que establecían con otros pueblos una posición de superioridad y buscaron su interés particular ante todo. No eran tan solidarios como Eneas - que, de todas formas, aceptaba unirse no a un pueblo cualquiera, sino al que le señalaron los dioses-. Ahora bien, el interés no es obstáculo para admitir el carácter integrador del Imperio Romano.

Finalmente, cabe ser señalado que fue Grecia la que acabó de dar sentido a la misión de $\mathrm{Roma}^{28}$. Ésta pronto fue admitida como una ciudad de origen griego por las interesadas oligarquías griegas que veían en Roma una alternativa mejor a la de las monarquías helenísticas que tutelaban sus ciudades. Esa admisión dentro del mundo griego significaba a la postre la justificación de su dominio en todo el Mediterráneo. Ya en el principado, intelectuales griegos contribuirán con sus obras a la legitimación del dominio universal romano ${ }^{29}$, presentándolo como unificador de un mundo sumido en conflictos hasta su instauración. Con Augusto, Italia había triunfado frente al Oriente encabezado por Cleopatra y Antonio, pero esto no significaba que renunciase a absorberlo; todo lo contrario. La misión de Roma se había salvado de nuevo, al igual que cuando Eneas había salido airoso del encuentro con Dido o Turno en su camino hacia la fundación del pueblo romano. El orden podía regresar al mundo; podía cumplirse el destino vaticinado por los dioses.

\section{EL FACTOR RELIGIOSO EN LA IDEA IMPERIAL}

El factor religioso está presente en la justificación de la mayoría de imperios. Es más, la legitimación de un imperio a partir de su misión acaba dando lugar a su sacralización. En su poema, Virgilio insiste en el respaldo divino recibido por el piadoso Eneas y utiliza explícitamente la participación activa de los dioses y de lo sobrenatural como señal de la veracidad del destino romano. Asimismo, en la Eneida las profecías tienen un papel fundamental, ya que son transmisoras del destino imperial de Roma. En este sentido, tres pasajes del poema son particularmente importantes: la profecía que Júpiter hace a Venus en el libro I, la revelación de Anquises a Eneas acerca de los futuros hombres ilustres que llevarán la gloria a Roma, en el libro VI, y las escenas que decoran el escudo fabricado por Vulcano para Eneas cuando es inminente la guerra contra Turno y los rútulos en Italia, en el libro VIII.

27 Aen. XII, 187-192.

28 PLÁCIDO SUÁREZ, D. “Graecia capta, integradora de la romanidad», en Studia Historia Historia Antigua, vol. VIII, 1990.

${ }_{29}$ Véase Dionisio de Halicarnaso, quien dedica bastante al relato de la llegada de Eneas al Lacio en el comienzo de su Historia Antigua de Roma. 
Los dioses, por tanto, están de parte de Eneas, y en el destino está marcado que el pueblo por él fundado alcanzará una gloria duradera. Incluso Juno, la diosa que lo persigue durante toda la aventura, acabará aceptando esto como algo inevitable. Júpiter le promete a Juno al final del libro XII que, a pesar de la victoria troyana en la guerra entablada en Italia, los latinos pervivirán, manteniendo su nombre, lengua y costumbres y absorberán a los teucros, que contribuirán a la alianza con sus leyes y sus ritos sagrados.

No debemos pasar por alto las dos cosas que aportan los troyanos: las leyes (tan importantes para el romano, como fundamento de su comunidad) y los ritos sagrados. Es decir, los troyanos dan sus Penates y trasladan su relación especial con los dioses a los latinos. Las buenas relaciones entre los romanos y sus dioses será uno de los pilares del programa ideológico augusteo. Un pueblo impío no tiene futuro. En cambio, el romano cuenta con un destino glorioso gracias en gran medida a su pietas ${ }^{30}$.

La propia Eneida era un libro profético, y así fue tomado por los romanos. Es una obra que trasciende la mera propaganda para instalarse en el ámbito de lo sagrado $^{31}$. Su autor, Virgilio, aparece en ella como un poeta uates que inspirado por los dioses - según el recurso arcaico de inspiración derivada de la acción de las Musas - narra los hechos pasados en los que se promete una gloria confirmada por los acontecimientos futuros ya conocidos, legitimando su presente con un pasado especular ${ }^{32}$. En la Eneida se entrecruzan tiempos diversos (el presente de Eneas y el futuro de su pueblo) que confirman que con Augusto, en el tiempo externo a la obra, se han cumplido las profecías alcanzándose la Nueva Edad de Oro.

En Virgilio, tal y como expone Hardie, los conceptos cosmos e imperium son indisociables, dado el carácter sagrado del Imperio. La historia de Roma es vista como una cosmogonía, en la que el orden se alcanza a través de los grandes hombres que, generación tras generación, Ilevan a Roma a la gloria. Esto queda plasmado en las tres profecías antedichas, sobre todo en la del escudo de Vulcano ${ }^{33}$. Puesto que ya hemos citado anteriormente las palabras de Júpiter, ahora nos detendremos en el escudo de Vulcano. El episodio de los Infiernos, en el libro VI, lo reservamos para el siguiente punto.

El escudo, en el que se hace un repaso de hechos destacados de la historia de Roma, presenta, en su parte central, el tema de la batalla de Actium. Para Hardie, esta escena es una gigantomaquia: en ella se enfrentan las fuerzas del orden y las

30 "Hinc genus Ausonio mixtum quod sanguine surget, / supra homines, supra ire deos pietate uidebis, / nec gens ulla tuos aeque celebrabit honores». Aen. XII, 837-840. Son palabras que Júpiter dirige a Juno.

${ }_{31}$ Un dato que no debemos olvidar es que la Eneida acabó siendo tomada como un verdadero oráculo por los romanos: las llamadas sortes virgilianae, consistentes en abrir el volumen de la Eneida al azar y leer el primer verso que se viese, fueron una de las varias formas que los romanos tuvieron en consideración para intentar saber algo acerca de su futuro. Según la Historia Augusta (Hadrianus, II), el propio Adriano recurrió a las sortes virgilianae antes de obtener el principado y en ellas se le habría revelado que acabaría consiguiéndolo al remitirlo a la figura de Numa Pompilio. El pasaje leído por Adriano fue Aen. VI 808-812.

32 MAS, S., op. cit. pp. 256-257.

33 HARDIE, P. Virgil's Aeneid: Cosmos and Imperium, Oxford Clarendon Press, 1986, p. 339. 
del caos, imponiéndose finalmente las primeras ${ }^{34}$. Los dioses grecolatinos, civilizados, garantes del cosmos y de la misión romana, están del lado de Augusto y Agripa, mientras que a Antonio y Cleopatra los ayudan divinidades monstruosas, como Anubis, que traen la muerte y la destrucción junto con la Discordia y las Furias.
«Omnigenumque deum monstra et latrator Anubis
contra Neptunum et Venerem contraque Mineruam
tela tenent. Saeuit medio in certamine Mauors
caelatus ferro, tristesque ex aethere Dirae,
et scissa gaudens uadit Discordia palla,
quam cum sanguineo sequitur Bellona flagello.
Actius haec cernens arcum intendebat Apollo»35.

El de Actium era un mito religioso además de nacional. Virgilio narra en él una victoria más importante que la hegemonía política: la que comportó la salvación del orden universal y de la justicia y virtudes romanas que lo sustentaban. La relación entre pietas y victoria es evidente. De hecho, Augusto exaltará sus victorias militares y diplomáticas no ya como simple reflejo de la uirtus romana, sino con el fin de «manifestar la relación entre el triunfo, la religión, el orden del Estado y el progreso en general» ${ }^{36}$. En los siguientes versos, el poeta continúa narrando cómo Vulcano había esculpido también la huida de Egipto, la entrada triunfal de Augusto en Roma, dedicando su victoria a los dioses y erigiendo tres centenares de templos, colocando los «dones de los pueblos» de las puertas del templo de Apolo en el Palatino, etc. Lo último que admira Eneas en el escudo es la representación de los pueblos o ríos que representaban los confines del mundo, a los que había llegado el dominio del pueblo romano. Todo ello es una imagen de la Pax Augusta.

Así pues, los dioses responden favorablemente en ayuda de Eneas al mostrarse éste en todo momento piadoso. La pietas es la clave de la que depende el cumplimiento de su destino. Una idea que también tuvo en consideración Augusto desde que asumió la dirección del Estado ${ }^{37}$ y que siempre había formado parte de la identidad romana tradicional. Sin los dioses y el debido respeto hacia ellos no existiría la posibilidad de tener esperanzas en un próspero futuro. Tampoco habría estabilidad si las profecías y la historia podían ser manipuladas por cualquiera que no fuese el princeps.

\section{UNA HISTORIA COMPLACIENTE: AUGUSTO Y LA MEMORIA INTERESADA}

Augusto, de entre las muchas enseñanzas que sacó del agónico final de la República, tuvo muy presente la fuerza que poseía el control de la transmisión de los hechos. Por eso durante su principado se dedicó a lo que Syme — no sin cierta ma-

34 Idem. p. 97.

35 Aen. VIII, 698-704. Nótese el papel destacado de Apolo, divinidad predilecta de Augusto.

36 ZANKER, P., op. cit., p. 222.

37 El Eneas del Ara Pacis y el del Foro de Augusto no es un guerrero, sino un hombre que destaca por su Pietas. Vid. ZANKER, P. Idem. pp. 240-243; GALINSKY, K., op. cit., p. 248. 
licia- llamó el «encauzamiento de la opinión pública»38. En esa pretensión, se valió de un programa de imágenes, entre las que podemos incluir las creadas por los poetas del círculo de Mecenas.

En la Eneida, Virgilio se vale de la historia de Roma para dar un respaldo material (y no sólo divino) a la idea imperial. Los hechos y hombres que llevaron a Roma a dominar el mundo sirven para mostrar la realidad de las profecías expuestas constantemente durante la obra. El romano podía basarse en su historia para confiar en un futuro próspero.

Por otro lado, esa historia romana se utiliza a favor del princeps. La figura de Augusto, además de estar siempre detrás de su alter ego Eneas, se cita expresamente como legítimo heredero de éste y continuador de la gran obra de los antepasados. En el principado augusteo se produce la culminación de la historia de Roma, ya que con él comienza una Noua Aurea Aetas, a partir del orden instaurado. Así, en los dos pasajes en los que Virgilio hace una relación de personajes relevantes de la historia romana (en el libro VI y en el libro VIII) Augusto aparece en un lugar destacadísimo.

El escudo de Vulcano (libro VIII), en el que sobresale la escena de la batalla de Actium, - momento cumbre de la historia romana al cimentarse en esa victoria el futuro del Imperio y, con él, el orden universal-, presenta, asimismo, imágenes de los orígenes de Roma: la loba amamantando a los gemelos, el episodio del rapto de las sabinas, la alianza de Rómulo y Tito Tacio, el castigo que Tulo Hostilio inflige a Meto por no cumplir con los deberes que le exigía el pacto que había sellado con los romanos (de nuevo, vemos, la relevancia de respetar los pactos), la amenaza de Lars Porsenna (y en relación con ella la valentía de Horacio Cocles, Clelia y Manlio) el episodio de los gansos alertando del ataque galo en 390 a.C, y las ofrendas hechas por el pueblo por la victoria de Camilo frente a Veyes. También aparece representado en el escudo el Tártaro donde son castigados los criminales que atentaron contra Roma, como Catilina. Y, además, "secretosque pios, his dantem iura Catonem ${ }^{39}$ (de nuevo las leyes). Con esta representación, culminada en la escena de Actium, Virgilio remarcaba la increíble trayectoria triunfal del pueblo romano, que de la nada había llegado a dominar el mundo y ser garante del orden universal. Esa cima histórica se había alcanzado gracias a la acción de Augusto, hombre piadoso y estimado por los dioses.

El otro pasaje en el que el poeta realiza una enumeración de los grandes hombres de la historia de Roma está en el libro VI, dentro de la revelación hecha por Anquises a su hijo Eneas ${ }^{40}$. Ese recuerdo de los grandes antepasados de los romanos es aquí más detallado. Se cita a algunos por su nombre y hechos y a otros sólo por una de las dos cosas ${ }^{41}$. Virgilio realiza una síntesis de varios siglos

38 SYME, R., op. cit, p. 575 y ss.

39 Aen. VIII, 670.

40 Aen. VI, 760-846.

41 Aparecen en el siguiente orden: algunos reyes de Alba Longa, Rómulo, Augusto, Numa Pompilio, Tulo Hostilio, Anco Marcio, los Tarquinios, Bruto, los Decios y Drusos, Torcuato, Camilo, César y Pom- 
de historia romana a través de los hombres que considera más sobresalientes, pero no por su repercusión en la historia romana (faltan, por ejemplo, Flaminino, Mario, Sila), sino por los valores personales y romanos que encarnan. La excepción la representan César y Pompeyo, quienes parecen citados como recuerdo de que la ambición particular no era piadosa, pues podía conducir al desorden civil.

Al margen de César y Pompeyo, los personajes que utiliza Virgilio son exempla uirtutum. Cada uno de ellos presenta alguna de las virtudes propiamente romanas, las cuales posee por completo el princeps. Numa Pompilio es el piadoso, Tulo Hostilio, el guerrero, Anco Marcio, el querido por el pueblo. Bruto, los Decios, y Torcuato son los hombres rigurosos entregados al servicio de la patria, que realizan las renuncias que sean necesarias ${ }^{42}$. Camilo es el caudillo victorioso entregado al servicio a la patria ${ }^{43}$, considerado el segundo fundador de la ciudad al evitar que se aceptase la propuesta de los tribunos de la plebe de abandonar Roma por la derrotada Veyes, y que además erigió un templo a la Concordia ${ }^{44}$. Lucio Mumio y Lucio Emilio Paulo representan la expresión de la superioridad de Roma sobre Grecia. Coso es ejemplo también de la uirtus roma$\mathrm{na}^{45}$. Fabricio es el incorruptible defensor de la austeridad y perseguidor del lujo. Qué decir de los Escipiones, quienes salvaron a Roma de la amenaza cartaginesa y extendieron su poder por Hispania y Oriente. Los Fabios murieron intentando acabar con Veyes a principios de la República y Fabius Maximus Cunctator, sucesor de éstos, quedó en el recuerdo como el infatigable hostigador de Aníbal. Finalmente, Marco Claudio Marcelo, cinco veces cónsul, sobresale como otra de las grandes figuras que contribuyeron a la derrota de Cartago durante la Segunda Guerra Púnica, además de ser quien tomó Siracusa y Agrigento, demostrando la superioridad romana sobre cartagineses y griegos, pero también la agudeza romana de saber admirar los logros culturales griegos, aprovechándolos en su beneficio.

Los Gracos citados por Virgilio no son los hermanos cuyas vidas y muertes estaban tan asociadas a la discordia civil, sino su abuelo y su padre. El primero fue un héroe de la guerra anibálica que murió en combate en este empeño; el segundo fue un hombre de relevancia en la Roma posterior a la Segunda Guerra Púnica, vinculado por matrimonio a la familia de los Escipiones, que destacó como general y por su austeridad y sobriedad. Eran, pues, los Sempronios Gracos una de las mejores familias nobles de Roma, como los Cornelios Escipiones, los Claudios o

peyo, Lucio Mumio, Lucio Emilio Paulo, Catón el Censor, Coso, la estirpe de los Gracos, la de los Escipiones, Fabricio, Serrano, los Fabios (remarcándose a Quinto Fabio Máximo el Contemporizador), y Marco Claudio Marcelo. Al final Eneas se fija en otro Marcelo, el yerno de Augusto, como un homenaje al joven, muerto prematuramente (lo que había supuesto un revés importante para el princeps).

42 Los Decios Mus ofrecieron su vida (en una deuotio) antes de la batalla para otorgar la victoria a Roma, Bruto condenó a muerte a sus hijos por conspirar contra la república y lo mismo hizo Torcuato con el suyo por desobedecer sus órdenes en combate y poner en riesgo la victoria romana.

${ }_{43}$ Salvó a Roma de la amenaza de Veyes (ciudad que destruyó) y de los galos en 390 a.C.

44 Augusto tuvo en Camilo una imagen muy poderosa con la que trazar fructíferos paralelismos.

45 En el primer siglo de la República, obtuvo los spolia opima tras vencer a Tolumnio, rey de Veyes. 
los Fabios, y con el ejemplo de sus antepasados Augusto quería conseguir la implicación en su régimen de sus sucesores ${ }^{46}$.

Se sabe que Augusto recurrió frecuentemente a ejemplos del pasado para respaldar muchas de sus medidas, sobre todo las más polémicas (como las que restringían el lujo). También se valió de los antepasados para legitimar su posición a la cabeza del Estado. En este pasaje del libro VI de la Eneida, las virtudes del princeps se expresan a través de cada uno de estos personajes, ninguno de los cuales era desconocido para los romanos; todo lo contrario, eran héroes muy reconocidos que en muchos casos formaban parte del mito de la ciudad. No es difícil ver la sombra de Augusto tras todos estos personajes, ni tampoco sacar en conclusión que en él convergía lo mejor de la tradición romana. Augusto era el mejor de los romanos, un exemplum uirtutum vivo ${ }^{47}$. Por otra parte, son muy evidentes las intenciones de Virgilio al citar a Augusto justo después de Rómulo: establece un paralelo entre ambos, siendo Augusto el nuevo fundador de Roma. También revela las aspiraciones dinásticas de éste.

Salvador Mas interpreta con perspicacia que «Virgilio enlaza con los primeros historiadores romanos que no conciben el pasado como una sucesión de acciones enlazadas casualmente que se implican entre sí (...), sino como la coexistencia histórica y a la vez atemporal de acontecimientos aislados que sin embargo están unidos como patrimonio común de valores coagulados bajo la forma de mos maiorum ${ }^{48}$. Virgilio, como buen poeta augusteo que era, entiende la utilidad de la historia romana desde un punto de vista moral y legitimista del orden establecido. La pretensión de regenerar la sociedad romana, de renovar la idea imperial, debía encauzarse por el recto seguimiento del ejemplo de los antepasados, cuyos valores (pietas, uirtus, iustitia, clementia, sobriedad, austeridad, rigor, amor a la patria, etc.) habían hecho grande a Roma.

\section{CONCLUSIÓN}

«Ponen los poetas el fundamento de lo permanente», sentenció Hölderlin, y Augusto, mejor que ningún otro, habría estado de acuerdo con él. La Eneida es Augusto y es su Roma. Así como representa el triunfo de un hombre en su lucha por la primacía política, también es, al mismo tiempo, la más lograda plasmación del sentir de un pueblo que necesitaba volver a confiar en su destino, a partir de la recuperación de la preciada paz interna. Augusto le ofreció todo eso a Italia a cambio

46 Y lo consiguió: Paulo Fabio Máximo fue uno de los amigos íntimos de Augusto (se dice que lo acompañó en su última visita, hecha en secreto, a Agripa Póstumo). Marco Claudio Marcelo estaba casado con su hermana Octavia y de su unión nació el Marcelo yerno de Augusto que fallecería repentinamente para consternación del princeps.

47 El programa de imágenes diseñado para el Foro de Augusto remarcaba esta condición de Augusto de heredero y partícipe de las cualidades de los grandes hombres de la historia de Roma, que culminaba en su principado. Nos referimos a la galería de Summi Viri. El elogium que cada estatua llevaba en su podio se dice que había sido compuesto por el propio Augusto. Vid. ZANKER, P., op. cit. pp. 251-252.

48 MAS, S., op. cit, p. 257. 
de la satisfacción de sus ambiciones políticas, presentándose como el digno sucesor de los grandes antepasados del pueblo romano, restaurador de los mores maiorum, y favorito de los dioses, en virtud de su ascendencia divina y de su pietas.

También es Roma porque en ella el poeta presenta los valores más puramente romanos (pasados, eso sí, por el tamiz del principado). No en vano su poema narra el origen del pueblo romano y el porqué de su ascenso hasta la dominación del mundo, gracias a su especial relación con los dioses y a sus virtudes (la uirtus y la pietas, sobre todo, además de la justicia). Eneas, trasunto de Augusto, es el referente. Asimismo, en la Eneida queda reflejada la concepción de Roma como idea universal: un imperio que no conoce límites, que asegura el orden cósmico, la salvaguarda de la paz y de la justicia y la perdurabilidad de éstas y de la prosperidad. Son, en efecto, los típicos cauces que siguen los imperios para legitimarse, en este caso integrados dentro del programa ideológico augusteo.

Zanker acertaba al señalar que «con un amplio programa cultural desarrollado consecuentemente durante más de veinte años se persiguió una renovación moral a todo nivel y se logró efectivamente un cambio de mentalidad. (...) contra la desidia respecto a los dioses y contra la inmoralidad se desarrolló un extraordinario movimiento de renovación religiosa y moral (pietas y mores) ${ }^{49}$. Todo este despliegue de imágenes no se puede entender sólo como mera propaganda legitimadora. Augusto creía en su programa ideológico ${ }^{50}$, y también Virgilio, pues los hechos jugaban a favor del primero. Toda población que ha vivido tiempos convulsos necesita recuperar la confianza en su mundo para seguir adelante.

La Eneida es la gran epopeya del pueblo romano y de su imperio no sólo por exaltar su destino y su dominación del mundo, sino por exponer en todas sus dimensiones la idea imperial que se hallaba tras su construcción política. El imperio romano llevó a la práctica un modelo innovador de sociedad, civil, basada en el ius, e integradora, y aseguró un orden universal que en los siglos posteriores a su caída fue tomada como la más elevada referencia por aquellos que ambicionaron reconstruirlo o legitimarse con la memoria del mismo.

\section{BIBLIOGRAFÍA}

ALBRECHT, M. v. Historia de la literatura romana desde Livio Andrónico hasta Boecio, vol. I, Barcelona, Herder, 1997 [Alemania, 1992].

BRUNT, P. A. «Laus Imperii», en GARNSEY, P. D. A; WHITTAKER, C. R. (eds.) Imperialism in the Ancient World. Cambridge University Press, 1978, pp. 159-191.

GALINSKY, K. Augustan culture: An interpretative introduction, Princeton University Press, 1998.

GARCÍA FERNÁNDEZ, E; RODRÍGUEZ MAYORGAS, A. «Tradición griega e identidad romana: la reflexión sobre los orígenes de Roma», en PLÁCIDO, D. et alii (eds.). La

\footnotetext{
49 ZANKER, P., op. cit. p. 19.

50 Coincido con Galinsky en la opinión de que Augusto no fue un mero líder transaccional, sino también y sobre todo un líder transformador. Vid. GALINSKY, K., op. cit. pp. 18-19.
} 
construcción ideológica de la ciudadanía: Identidades culturales y sociedad en el mundo griego. Madrid, Editorial Complutense, 2006.

GRIMAL, P. El siglo de Augusto, Madrid, FCE, 1996 [París, 1955].

HARDIE, P. Virgil's Aeneid: Cosmos and Imperium, Oxford, Clarendon Press, 1986.

LÓPEZ BARJA DE QUIROGA, P. Imperio legítimo: El pensamiento político en tiempos de Cicerón, Madrid, Antonio Machado Libros, 2007.

MARROU, H.-I. Historia de la educación en la Antigüedad, Madrid, Akal, 2004.

MARTINDALE, Ch. (ed.). The Cambridge companion to Virgil, Cambridge University Press, 1997.

MAS, S. Pensamiento romano: Una historia de la filosofía en Roma, Valencia, Tirant lo Blanch, 2006.

MOATTI, C. La razón de Roma: El nacimiento del espíritu crítico a fines de la República. Madrid: Antonio Machado Libros, 2008 [París, 1997].

MÜNKLER, H. Empires: The Logic of World Domination from Ancient Rome to the United States, Cambridge, Polity Press, 2007.

PLÁCIDO SUÁREZ, D. «Graecia capta, integradora de la romanidad», en Studia Historia Historia Antigua, vol. VIII, 1990.

REED, J. D. Virgil's gaze: Nation and poetry in the Aeneid. Princeton University Press, 2007.

RODRÍGUEZ MAYORGAS, A. La memoria de Roma: oralidad, escritura e historia en la República romana. Oxford, BAR International Series 1641, 2007.

SYME, R. La revolución romana. Madrid, Taurus, 1989 [Oxford, 1939].

ZANKER, P. Augusto y el poder de las imágenes. Madrid, Alianza Editorial, 2005 [Munich, 1987]. 